${ }^{1}$ Gloucestershire Eye Department, Cheltenham General Hospital, Gloucestershire Hospitals NHS Foundation Trust, Cheltenham, Gloucestershire, UK ${ }^{2}$ Department of Ophthalmology, Bristol Eye Hospital, United Bristol Healthcare NHS Trust, Bristol, UK

${ }^{3}$ Department of Ophthalmology, St James' University Hospital, Leeds Teaching Hospitals NHS Trust, Leeds, UK

${ }^{4}$ Department of Ophthalmology, Clayton Eye Centre, Pinderfields and Pontefract Hospitals NHS Trust, Wakefield, UK

${ }^{5}$ Department of

Ophthalmology, Norfolk and Norwich University Hospital, Norfolk and Norwich University Hospitals NHS Trust, Norwich, UK

${ }^{6}$ International Centre for Eye Health, London School of Hygiene and Tropical Medicine, University of London, London, UK

Correspondence: RL Johnston, Gloucestershire Eye Department, Cheltenham General Hospital, Gloucestershire Hospitals NHS Foundation Trust, Sandford Road, Cheltenham, Gloucestershire, GL53 7AN, UK.

Tel: + 441242 272529; Fax: + 441242272585 . E-mail: Rob.Johnston@ glos.nhs.uk

Received: 6 November 2007 Accepted: 19 November 2007 Published online: 8 February 2008

\section{The Cataract National Dataset electronic multicentre audit of 55567 operations: antiplatelet and anticoagulant medications}

\begin{abstract}
Aims This study aims to establish the prevalence of aspirin, dipyridamole, clopidogrel, and warfarin use in patients undergoing cataract surgery, and to compare local anaesthetic and intraoperative complication rates between users and non-users. Methods The Cataract National Dataset was remotely extracted and anonymised on 55567 operations at 12 NHS Trusts using electronic patient records (EPRs) between 2001 and 2006. Results This report analyses 48862 of the 55567 operations from the eight centres, which

Conclusions Clopidogrel or warfarin use was associated with a significant increase in minor complications of sharp needle and subtenon's cannula local anaesthesia but was not associated with a significant increase in potentially sight-threatening local anaesthetic or operative haemorrhagic complications. Eye (2009) 23, 10-16; doi:10.1038/sj.eye.6703069; published online 8 February 2008

Keywords: cataract surgery; Cataract National Dataset; complications; haemorrhage; antiplatelet; anticoagulant
\end{abstract} routinely recorded a drug history. In all, $28.1 \%$ of the 48862 patients were taking aspirin, $5.1 \%$ warfarin, $1.9 \%$ clopidogrel, and $1.0 \%$ dipyridamole. The recording of any complication of a sharp needle or subtenon's cannula local anaesthetic block was increased in patients taking clopidogrel, $8.0 \%$ $(P<0.0001)$ or warfarin, $6.2 \%(P=0.0026)$ vs non-users, $4.3 \%$, but no increase in potentially sight-threatening complications was identified. The incidence of subconjunctival haemorrhage was increased in patients taking clopidogrel, $4.4 \%(P<0.0001)$ or warfarin, $3.7 \%$ $(P<0.0001)$ vs non-users, $1.7 \%$. The recording of any operative complication was increased in those taking clopidogrel, $7.3 \%(P=\mathbf{0 . 0 0 0 2})$ vs non-users, $4.4 \%$, but the haemorrhagic operative complications of choroidal/ suprachoroidal haemorrhage and hyphaema were not significantly increased. The non-haemorrhagic complication of posterior capsular rupture (PCR) was increased in those taking clopidogrel, $3.23 \%(P=0.0057)$ vs non-users, $1.77 \%$.
JD Benzimra', RL Johnston', P Jaycock², PH Galloway ${ }^{3}$ G Lambert ${ }^{3}$, AKK Chung ${ }^{4}$, T Eke ${ }^{5}$, JM Sparrow ${ }^{2,6}$ and the EPR User Group
Introduction

The vast majority of patients undergoing cataract surgery are elderly and take regular systemic medications. During the cataract care pathway, it is a normal practice in the United Kingdom, usually at a nursing pre-assessment visit, to take a drug history. Important classes of drugs to identify include antiplatelet and anticoagulant medications, which may increase the risk of haemorrhagic anaesthetic or operative complications. These medications are, however, taken to reduce the incidence of potentially life-threatening thromboembolic events in patients with cardiovascular conditions; ${ }^{1-5}$ therefore, so long as they do not threaten the success of cataract surgery, it is desirable to continue them before surgery.

The management of patients taking aspirin or warfarin at the time of cataract surgery has previously been investigated. The largest reported series involved 19283 cataract 
operations, ${ }^{6}$ which in common with other reports, did not identify an increased risk of haemorrhagic complications during local anaesthesia ${ }^{6,7}$ or cataract surgery. ${ }^{6,8}$ Other studies have reported an increased risk of minor haemorrhagic, but not visually threatening complications in patients taking warfarin. ${ }^{10-14}$ The Royal College of Ophthalmologists' Cataract Surgery

Guidelines (2004) recommends that patients taking aspirin should continue it before cataract surgery, and patients taking warfarin should continue this medication but that the INR should be within the therapeutic level. ${ }^{15}$ These guidelines were predominantly based on a 2001 literature review. ${ }^{16}$

Clopidogrel and dipyridamole are newer antiplatelet medications and have not been subject to the same scrutiny as potential risk factors for haemorrhagic complications during cataract surgery. Clopidogrel use has been shown to increase the risk of bleeding associated with coronary artery bypass surgery ${ }^{17,18}$ and in other procedures. ${ }^{19}$ Dipyridamole has been shown to produce no increase in haemorrhage during cardiac surgery. ${ }^{20}$ A case of unexpected bleeding during phacoemulsification in a patient on aspirin and clopidogrel has been reported. ${ }^{21}$ Only one small study has addressed the risk of clopidogrel in cataract surgery, focusing exclusively on subtenon's anaesthesia. ${ }^{22}$ In this study, 40 patients on clopidogrel and 65 patients on warfarin were found to have a significant increase in the incidence of subconjunctival haemorrhage compared to controls but no sight-threatening haemorrhagic complications occurred in any patients.

This paper aims to document the prevalence of the use of anticoagulant and antiplatelet medications in patients undergoing cataract surgery, and to compare the incidence of local anaesthetic and intraoperative complications between users and non-users.

\section{Materials and methods}

The methods employed in this study have been described in detail in the first paper in this series. ${ }^{23}$ Briefly, the Cataract National Dataset (CND) ${ }^{24}$ was remotely extracted on 55567 cataract operations performed between November 2001 and July 2006, from 12 NHS trusts that all used the same electronic patient record (EPR) system (Medisoft Ophthalmology, Medisoft Limited, Leeds, UK; http://www.medisoft.co.uk).

For this study, only data from the eight sites that routinely recorded a drug history as part of the nursing pre-assessment were included in the analysis. Patients not on antiplatelet or anticoagulant medications formed the comparison group.

Either the anaesthetist or the operating surgeon could complete the anaesthetic data collection fields. To balance completeness, speed, and accuracy of data entry, the EPR allows some fields to be defaulted for individual surgeons or anaesthetists (eg, grade, anaesthetic technique, usual anaesthetic drugs used, and many of the operative technique fields), but a compulsory choice must be made each time the anaesthetic or operative complication fields are completed. In earlier versions of this software, the anaesthetic complications field was only available for sharp needle and subtenon's cannula local anaesthetic techniques, and it was not possible to record an anaesthetic complication of topical/ intracameral anaesthesia. This, therefore, limits our ability to comment on complications of topical or intracameral anaesthesia, but haemorrhagic complications would not be expected with these techniques. For the purpose of this report, anaesthetic or operative complications were defined by the authors as serious if they were considered to be potentially life-threatening (systemic) or sight threatening (ocular/ orbital), and minor if worthy of recording but not in the serious category. The haemorrhagic complications of anaesthesia available on the EPR were subconjunctival haemorrhage, eyelid haemorrhage/bruising, and retrobulbar/peribulbar haemorrhage. The haemorrhagic operative complications available were hyphaema and choroidal/suprachoroidal haemorrhage.

Dichotomous variables were compared by the $\chi^{2}$ or Fisher's exact tests as appropriate. Continuous variables were compared with unpaired $t$-tests. A $P$-value of less than 0.05 was considered statistically significant (two tailed). Because an unknown number of operations were performed on two eyes of the same patient in this dataset, caution is advised when interpreting results where $0.05<P<0.01$. Analyses were performed using iStat software (http:/ /www.handango.com).

\section{Results}

The Cataract National Dataset was remotely extracted on 55567 cataract operations performed between November 2001 and July 2006 at 12 NHS Trusts widely scattered throughout the United Kingdom. For this study, analysis was restricted to the 48862 cataract operations performed at eight NHS Trusts, where the EPR system was routinely used to record a reliable drug history.

Of the 48862 operations performed at sites that routinely recorded drug history, 41006 or $83.9 \%$ were recorded as taking one or more medications preoperatively with 16961 or $34.7 \%$ taking one or more antiplatelet or anticoagulant medications. Overall, aspirin was used in $28.1 \%$, warfarin in $5.1 \%$, clopidogrel in $1.9 \%$, and dipyridamole in $1.0 \%$ (Table 1). In all, $1.3 \%$ of operations performed were on eyes of patients who were taking more than one of these medications. Further, 
Table 1 Absolute numbers of patients on each medication, and patient characteristics $(N=48862$. Note, 639 patients took more than one medication, and 71 patients did not have gender recorded)

\begin{tabular}{|c|c|c|c|c|c|}
\hline $\begin{array}{l}\text { Antiplatelet/ } \\
\text { anticoagulant used }\end{array}$ & Total & Age (range) & $\begin{array}{l}\text { Gender } \\
\text { Male: } \\
\text { Female: }\end{array}$ & Diabetes & $\begin{array}{l}\text { Copathology predictive of } \\
\text { poor visual outcome }\end{array}$ \\
\hline None (comparison) & $31901(65.3 \%)$ & $74.2(5-104)$ & $\begin{array}{c}\text { M: } 10990(34.5 \%), \\
\text { F: } 20864(65.4 \%)\end{array}$ & $3225(10.1 \%)$ & $8865(27.8 \%)$ \\
\hline Aspirin & $13717(28.1 \%)$ & $\begin{array}{c}77.9(38-103) \\
P<0.0001\end{array}$ & $\begin{array}{c}\text { M: } 5961(43.5 \%), \\
\text { F: } 7737(56.4 \%)\end{array}$ & $\begin{array}{c}3155(23.0 \%) \\
\chi^{2}=132.41 \\
P<0.0001\end{array}$ & $\begin{array}{c}3994(29.1 \%) \\
\chi^{2}=8.29 \\
P=0.0038\end{array}$ \\
\hline Clopidogrel & $933(1.9 \%)$ & $\begin{array}{c}76.8(46-97) \\
P<0.0001\end{array}$ & $\begin{array}{c}\text { M: } 431(46.2 \%), \\
\text { F: } 500(53.6 \%)\end{array}$ & $\begin{array}{c}195(20.9 \%) \\
\chi^{2}=113.12 \\
P<0.0001\end{array}$ & $\begin{array}{c}286(30.7 \%) \\
\chi^{2}=3.56 \\
P=0.0665\end{array}$ \\
\hline Dipyridamole & $471(1.0 \%)$ & $\begin{array}{c}79.3(43-97) \\
P<0.0001\end{array}$ & $\begin{array}{c}\text { M: } 240(51.0 \%), \\
\text { F: } 231(49.0 \%)\end{array}$ & $\begin{array}{c}109(23.1 \%) \\
\chi^{2}=83.93 \\
P<0.0001\end{array}$ & $\begin{array}{c}151(32.1 \%) \\
\chi^{2}=4.0024 \\
P=0.0508\end{array}$ \\
\hline Warfarin & $2485(5.1 \%)$ & $\begin{array}{c}78.3(29-96) \\
P<0.0001\end{array}$ & $\begin{array}{c}\text { M: } 1221(49.1 \%), \\
\text { F: } 1261(50.7 \%)\end{array}$ & $\begin{array}{c}452(18.2 \%) \\
\chi^{2}=157.60 \\
P<0.0001\end{array}$ & $\begin{array}{c}661(26.6 \%) \\
\chi^{2}=1.5698 \\
P=0.2227\end{array}$ \\
\hline
\end{tabular}

31901 or $65.3 \%$ of the operations were on patients who were not on any anticoagulant on antiplatelet medications, and they formed the comparison group (Table 1).

The mean age was significantly higher in patients on aspirin (77.9 years, $P<0.0001)$, clopidogrel (76.8 years, $P<0.0001)$, dipyridamole (79.3 years, $P<0.0001)$, or warfarin (78.3 years, $P<0.0001)$ than in patients in the comparison group (74.2 years; Table 1 ). There was a significant increase in the recording of a preoperative eye condition predictive of a poor visual prognosis in those taking aspirin $(29.1 \%, P=0.0038)$ compared with those not on antiplatelet or anticoagulant medications (27.8\%). Recording of preoperative copathology predictive of poor visual outcome was not significantly increased in those on warfarin, clopidogrel, or dipyridamole (Table 1). Diabetes was present significantly in more patients taking aspirin $(23.0 \%, P<0.0001)$, clopidogrel $(20.9 \%$, $P<0.0001)$, dipyridamole $(23.1 \%, P<0.0001)$, or warfarin (22.2\%, $P<0.0001)$ compared to those not on such medications $(10.1 \%)$.

\section{Complications of local anaesthetic}

Operations performed under topical alone or combined topical and intracameral anaesthesia were excluded for reasons of data completeness in relation to recording of local anaesthetic complications. Sharp needle or subtenon's cannula anaesthesia was used in 32686 or $66.9 \%$ of cases. Of these, 11685 or $35.7 \%$ of blocks were in patients taking one or more anticoagulant or antiplatelet medications, with the remaining 21001 or $64.3 \%$ of blocked cases not using such medications, and forming the relevant comparison group (Table 2).
The incidence of any complication of local anaesthesia was significantly higher in those on clopidogrel alone, $8.0 \%(P<0.0001)$ or warfarin alone, 6.2\% $(P=0.0026)$ than in the control group, $4.3 \%$. There was no significant increase in the overall recording of complications of sharp needle and subtenon's cannula local anaesthesia in those on aspirin or dipyridamole, or those on aspirin used in combination with clopidogrel, warfarin, or dipyridamole (Table 2).

Of the haemorrhagic complications, the recording of subconjunctival haemorrhage was significantly increased in those on clopidogrel alone, $4.4 \%(P<0.0001)$ and in those on warfarin alone, $3.7 \%(P<0.0001 \%)$, as well as those on a combination of aspirin and warfarin $6.6 \%$ $(P=0.0041)$ compared to those not on antiplatelet or anticoagulant medications, $1.7 \%$. No significant difference in the recording of subconjunctival haemorrhage was observed in those on aspirin or dipyridamole alone, or aspirin in combination with clopidogrel or dipyridamole (Table 2). No significant increase in eyelid haemorrhage/bruising was found in any group. No significant increases in the potentially sight-threatening haemorrhagic complications of retrobulbar/peribulbar haemorrhage were found in any of the anticoagulant or antiplatelet groups.

\section{Operative complications}

Data on operative complications were available for all 48862 operations. Patients on clopidogrel alone had a significant increase in the recording of any operative complications, $7.3 \%(P=0.0002)$ vs $4.4 \%$ in the comparison group. No increase in the recording of any operative complications was found in any other group 
Table 2 Complications of sharp needle and subtenon's cannula local anaesthesia vs medications used ( $N=32656$. Note, 30 patients on other combinations of medications excluded from the table due to small group numbers)

\begin{tabular}{|c|c|c|c|c|c|}
\hline $\begin{array}{l}\text { Antiplatelet/ } \\
\text { anticoagulant used }\end{array}$ & Total & $\begin{array}{c}\text { Any complication } \\
\text { of } L A\end{array}$ & $\begin{array}{l}\text { Subconjunctival } \\
\text { haemorrhage }\end{array}$ & $\begin{array}{c}\text { Eyelid haemorrhage/ } \\
\text { bruising }\end{array}$ & $\begin{array}{c}\text { Retrobulbar/ } \\
\text { Peribulbar haemorrhage }\end{array}$ \\
\hline None (comparison) & 21001 & $894(4.3 \%)$ & $353(1.68 \%)$ & $44(0.21 \%)$ & $7(0.03 \%)$ \\
\hline Aspirin only & 9101 & $\begin{array}{c}406(4.5 \%) \\
\text { NS } \\
\chi^{2}=0.5917, \\
P=0.4385\end{array}$ & $\begin{array}{c}182(2.00 \%) \\
\text { NS } \\
\chi^{2}=3.3885 \\
P=0.0738\end{array}$ & $\begin{array}{c}28(0.31 \%), \\
\text { NS, } \\
\chi^{2}=2.1562, \\
P=0.156\end{array}$ & $\begin{array}{c}4(0.04 \%), \\
\text { NS, } \\
\chi^{2}=0.6661, \\
P=0.8388\end{array}$ \\
\hline Clopidogrel only & 524 & $\begin{array}{l}42(8.0 \%) \\
\chi^{2}=16.46 \\
P<0.0001\end{array}$ & $\begin{array}{c}23(4.39 \%) \\
\chi^{2}=20.3 \\
P<0.0001\end{array}$ & $\begin{array}{c}1(0.19 \%) \\
\text { NS }\end{array}$ & $\begin{array}{c}0, \\
\text { NS }\end{array}$ \\
\hline Dipyridamole only & 78 & $\begin{array}{c}3(3.8 \%) \\
\text { NS, } \\
\chi^{2}=0.0119, \\
P=0.84\end{array}$ & $\begin{array}{c}2(2.56 \%) \\
\text { NS }\end{array}$ & $\begin{array}{l}0, \\
\text { NS }\end{array}$ & $\begin{array}{l}0, \\
\text { NS }\end{array}$ \\
\hline Warfarin only & 1525 & $\begin{array}{r}95(6.2 \%) \\
\chi^{2}=8.9123 \\
P=0.0026\end{array}$ & $\begin{array}{l}56(3.67 \%) \\
\chi^{2}=30.52 \\
P<0.0001\end{array}$ & $\begin{array}{c}4(0.26 \%) \\
\text { NS } \\
\chi^{2}=0.207 \\
P=0.8303\end{array}$ & $\begin{array}{l}0, \\
\text { NS }\end{array}$ \\
\hline Aspirin + clopidogrel & 134 & $\begin{array}{c}6(4.5 \%), \\
\text { NS, } \\
\chi^{2}=0.0078, \\
P=0.8445\end{array}$ & $\begin{array}{l}4(2.99 \%) \\
\quad \text { NS }\end{array}$ & $\begin{array}{c}1(0.75 \%) \\
\text { NS }\end{array}$ & $\begin{array}{l}0, \\
\text { NS }\end{array}$ \\
\hline Aspirin + dipyridamole & 217 & $\begin{array}{c}9(4.1 \%) \\
\text { NS } \\
\chi^{2}=0.008 \\
P=0.8443\end{array}$ & $\begin{array}{c}2(0.92 \%) \\
\quad \text { NS }\end{array}$ & $\begin{array}{c}0, \\
\text { NS }\end{array}$ & $\begin{array}{c}1(0.46 \%) \\
\text { NS }\end{array}$ \\
\hline Aspirin + warfarin & 76 & $\begin{array}{c}7(9.2 \%) \\
\text { NS, Yates, } \\
\chi^{2}=3.411 \\
P=0.0728\end{array}$ & $\begin{array}{l}5(6.58 \%) \\
\chi^{2}=8.15 \\
P=0.0041\end{array}$ & $\begin{array}{c}1(1.32 \%) \\
\text { NS }\end{array}$ & $\begin{array}{l}0, \\
\text { NS }\end{array}$ \\
\hline
\end{tabular}

(Table 3). No significant increase in the potentially sight-threatening haemorrhagic complications of choroidal/suprachoroidal haemorrhage or hyphaema was identified in any group (Table 3). Clopidogrel use was associated with a significant increase in the recording of posterior capsule rupture (PCR) with or without vitreous loss, $3.23 \%(P=0.0057)$ vs $1.77 \%$ in the comparison group. No significant increase in PCR was identified in any other group, including those on combined aspirin and clopidogrel.

\section{Discussion}

This study of the use of anticoagulant and antiplatelet medication in patients undergoing cataract surgery is the largest ever reported. We have identified the prevalence of aspirin and warfarin use in the UK cataract population as 28.1 and $5.1 \%$, respectively, higher than the reported prevalence in a large study of cataract operations performed in the United States and Canada. ${ }^{6}$ Clopidogrel is used in $1.9 \%$ of patients undergoing cataract surgery and dipyridamole in $1.0 \%$ and patients using these medications will, therefore, be encountered regularly. We have identified an increase in the overall recording of sharp needle and subtenon's cannula local anaesthetic complications, in particular, an increase in subconjunctival haemorrhage in patients using clopidogrel or warfarin. Furthermore, clopidogrel use was associated with a significant increase in the overall recording of operative complications, including a significant increase in posterior capsule rupture. Perhaps, most importantly, we did not demonstrate an increased risk of serious haemorrhagic complications in patients using any antiplatelet or anticoagulant medications.

Our review of the patient characteristics of those on anticoagulant and antiplatelet medications demonstrate significant differences, compared with the comparison group that may act as confounding factors when considering anaesthetic or operative complication rates. Patients taking any antiplatelet or anticoagulant medications were on average older and more likely to have diabetes. However, only patients taking aspirin demonstrated a significant increase in the recording of preoperative ocular copathology predictive of a poor visual outcome, although colpidogrel use $(P=0.0665$ and 
Table 3 Intraoperative complications $v$ s medications used $(N=48824$. Note, 38 patients on other combinations of medications excluded from the table due to small group numbers)

\begin{tabular}{|c|c|c|c|c|c|}
\hline $\begin{array}{l}\text { Antiplatelet/ } \\
\text { anticoagulant used }\end{array}$ & Total & $\begin{array}{l}\text { Any operative } \\
\text { complication }\end{array}$ & $\begin{array}{c}\text { Choroidal/suprachoroidal } \\
\text { haemorrhage }\end{array}$ & Hyphaema & $\begin{array}{l}\text { Posterior capsule } \\
\text { rupture }\end{array}$ \\
\hline None (comparison) & 31901 & $1407(4.4 \%)$ & $22(0.07 \%)$ & $14(0.04 \%)$ & $564(1.77 \%)$ \\
\hline Aspirin only & 13110 & $\begin{array}{c}575(4.4 \%) \\
\text { NS }\end{array}$ & $\begin{array}{c}7(0.05 \%), \\
\text { NS, } \\
\chi^{2}=0.1498 \\
P=0.7046\end{array}$ & $\begin{array}{c}8(0.06 \%) \\
\text { NS }\end{array}$ & $\begin{array}{c}248(1.89 \%) \\
\text { NS } \\
\chi^{2}=0.7345 \\
P=0.3878\end{array}$ \\
\hline Clopidogrel only & 712 & $\begin{array}{l}52(7.3 \%) \\
\chi^{2}=12.97 \\
P=0.0002\end{array}$ & $\begin{array}{c}2(0.28 \%) \\
\text { NS } \\
\chi^{2}=1.86 \\
P=0.187\end{array}$ & $\begin{array}{c}1(0.14 \%) \\
\text { NS, } \\
\chi^{2}=0.092 \\
P=0.7571\end{array}$ & $\begin{array}{c}23,(3.23 \%) \\
\chi^{2}=7.6194 \\
P=0.0057\end{array}$ \\
\hline Dipyridamole only & 128 & $\begin{array}{c}5(3.9 \%) \\
\text { NS, } \\
\chi^{2}=0.0038 \\
P=0.849\end{array}$ & $\begin{array}{c}0, \\
\text { NS }\end{array}$ & $\begin{array}{c}0, \\
\text { NS }\end{array}$ & $\begin{array}{c}3(2.34 \%) \\
\text { NS } \\
\chi^{2}=0.0247 \\
P=0.826\end{array}$ \\
\hline Warfarin only & 2372 & $\begin{array}{c}90(3.8 \%), \\
\text { NS, } \\
\chi^{2}=1.86 \\
P=0.1864\end{array}$ & $\begin{array}{c}1(0.04 \%) \\
\quad \mathrm{NS}\end{array}$ & $\begin{array}{c}2(0.08 \%), \\
\text { NS, } \\
\chi^{2}=0.1497, \\
P=0.7047\end{array}$ & $\begin{array}{c}38(1.60 \%), \\
\text { NS, } \\
\chi^{2}=0.2627, \\
P=0.6156\end{array}$ \\
\hline Aspirin + clopidogrel & 190 & $\begin{array}{c}8(4.2 \%) \\
\text { NS }\end{array}$ & $\begin{array}{c}0, \\
\text { NS }\end{array}$ & $\begin{array}{l}0, \\
\text { NS }\end{array}$ & $\begin{array}{c}4(2.11 \%) \\
\text { NS } \\
\chi^{2}=0.0057, \\
P=0.8469\end{array}$ \\
\hline Aspirin + dipyridamole & 317 & $\begin{array}{c}19(6.0 \%), \\
\text { NS, } \\
\chi^{2}=1.5043, \\
P=0.2317\end{array}$ & $\begin{array}{l}0, \\
\text { NS }\end{array}$ & $\begin{array}{l}0, \\
\text { NS }\end{array}$ & $\begin{array}{c}5(1.58 \%), \\
\text { NS, } \\
\chi^{2}=0.0018 \\
P=0.8513\end{array}$ \\
\hline Aspirin + warfarin & 94 & $\begin{array}{c}5(5.3 \%) \\
\text { NS, } \\
\chi^{2}=0.0313 \\
P=0.819\end{array}$ & $\begin{array}{c}0, \\
\text { NS }\end{array}$ & $\begin{array}{c}0, \\
\text { NS }\end{array}$ & $\begin{array}{c}3(3.19 \%), \\
\text { NS, } \\
\chi^{2}=0.4265, \\
P=0.5164\end{array}$ \\
\hline
\end{tabular}

dipyridamole use $(P=0.0508)$ did come close to significant levels.

The analysis of local anaesthetic complications was restricted to complications of sharp needle and subtenon's cannula local anaesthesia (66.9\%). These were deemed to be the situations where haemorrhagic complications of the anaesthetic were most relevant and, as indicated in the methods, anaesthetic complications data were not available for topical/intracameral anaesthetic techniques. The overall recording of a complication of local anaesthesia was significantly higher in those on clopidogrel or warfarin. In keeping with previous studies, there was an increase in subconjunctival haemorrhage rates in those on clopidogrel or warfarin, ${ }^{22}$ although the overall recorded rates were almost ten-fold lower in our study.

Underreporting bias is a feature of all major studies of complications of local anaesthesia and are discussed in full in our paper on local anaesthetic techniques and complications. ${ }^{25}$ No sight-threatening haemorrhagic complications (retrobulbar/peribulbar haemorrhage) were recorded as a complication of sharp needle or subtenon's cannula local anaesthesia in patients on clopidogrel or warfarin alone, or when used in combination with aspirin. Retrobulbar/peribulbar haemorrhage was recorded for four local anaesthetics in patients on aspirin $(0.044 \%)$ and one on combined aspirin and dipyridamole $(0.461 \%)$, but this was not significantly different from controls $(0.033 \%)$. Serious haemorrhagic complications of local anaesthesia are very uncommon, and, even with this large sample size, the rate would have had to be $>4$-fold higher $(>0.13 \%)$ among aspirin users than control groups for our sample to have had $80 \%$ power to detect a difference. Similarly, this study does not have sufficient statistical power to draw conclusions about the incidence of potentially sightthreatening haemorrhagic local anaesthetic complications in patients on clopidogrel or warfarin. From our sample, we can however exclude substantial excess rates, ie, this sample would have $80 \%$ power to detect a $>14$-fold excess rate for clopidogrel and a $>8$-fold excess for warfarin (two tailed). The absence of any reported case of retrobulbar/peribulbar haemorrhage or expulsive/suprachoroidal haemorrhage in 524 patients on clopidogrel and 1525 on warfarin does suggest a low incidence, which is important if 
considering stopping medications, an approach that may have serious systemic implications.

The analysis of operative complications was carried out on 48862 operations. Patients on clopidogrel showed a significantly higher overall incidence of any operative complication than the comparison group. Antiplatelet and anticoagulant use was, however, not associated with a higher incidence of the haemorrhagic operative complications of choroidal/suprachoroidal haemorrhage or hyphaema. Unexpectedly, clopidogrel use was identified as being associated with a significantly increased rate of the non-haemorrhagic complication of posterior capsule rupture. It is possible that this finding reflects a difference in the characteristics of patients receiving clopidogrel. These patients, as previously noted, were on average significantly older than those in the comparison group, but did not have significantly higher rates of copathology recorded. This unexpected finding is difficult to understand but could reflect 'surgical difficulty', where there is increased superficial haemorrhage or simply the fact that users were older, an association highlighted in our previously reported multivariate analysis of risk factors for posterior capsule rupture or vitreous loss or both. ${ }^{26}$

Data for this study were extracted from the EPR system in accordance with the CND and some of the potential shortcomings of the analysis in this study may reflect limitations of the CND. Most notable for this analysis, there is no indication in the extracted data as to whether the anticoagulant/antiplatelet medication was stopped before surgery or, if the patient was on warfarin, whether an INR was performed or its result.

Underreporting bias of operative complications is also a potential problem in any study of this kind, but with both anaesthetic and operative complications, the EPR system used does force the user to answer the question in $100 \%$ of the cases.

Although the numbers of operations involved in this analysis are large, the numbers of patients on some combinations of aspirin, dipyridamole, clopidogrel, or warfarin are small and are of limited use for analysis, particularly, of rare complications. Aspirin taken with clopidogrel $(n=190)$ or warfarin $(n=94)$ was encountered regularly enough to merit inclusion in the analysis, and dipyridamole was actually encountered more frequently in combination with aspirin $(n=317)$ than dipyridamole alone $(n=128)$, reflecting the availability of and indication for dipyridamole combined with aspirin as a second-line treatment in stroke prevention. ${ }^{5}$ With increased EPR uptake future similar analyses of even larger samples may shed light on these questions.

The Cataract Do Once and Share ${ }^{27}$ programme has facilitated the collection of the details of 55567 operations for audit purposes. The use of EPRs allows information to be recorded in accordance with the $\mathrm{CND},{ }^{24}$ which is then readily available for audit purposes. Observational information on rare events and interactions is made possible at minimal cost in areas where expense and logistical limitations preclude randomised controlled trials. ${ }^{28}$ This paper has addressed specific questions regarding the use and complications of anticoagulant and antiplatelet medications in patients undergoing cataract surgery.

\section{Acknowledgements}

This study was supported by the Cataract Do Once and Share Initiative and the EPR Users Group.

Financial interest declaration:

RL Johnston is a Director of Medisoft Limited.

\section{References}

1 EAFT (European Atrial Fibrillation Trial) Study Group. Secondary prevention in non-rheumatic atrial fibrillation after transient ischaemic attack or minor stroke. Lancet 1993; 342: 1255-1262.

2 Petersen P, Boysen G, Godtfredsen J, Andersen ED, Andersen B. Placebo-controlled, randomised trial of warfarin and aspirin for prevention of thromboembolic complications in chronic atrial fibrillation. The Copenhagen AFASAK study. Lancet 1989; 1: 175-179.

3 The ISIS-2 (Second International Study of Infarct Survival) Collaborative GroupBaigent C, Collins R, Appleby P, Parish S, Sleight P, Peto R. ISIS-2: 10 year survival among patients with suspected acute myocardial infarction in randomised comparison of intravenous streptokinase, oral aspirin, both, or neither. BMJ 1998; 316: 1337-1343.

4 CAPRIE Steering Committee. A randomised, blinded, trial of clopidogrel $v s$ aspirin in patients at risk of ischaemic events (CAPRIE). Lancet 1996; 348: 1329-1339.

5 ESPIRIT Study GroupHalkes PH, van Gijn J, Kappelle LJ, Koudstaal PJ, Algra A. Aspirin plus dipyridamole vs aspirin alone after cerebral ischaemia of arterial origin (ESPIRIT): randomized controlled trial. Lancet 2006; 367: 1665-1673.

6 Katz J, Feldman MA, Bass EB, Lubomski LH, Tielsch JM, Petty BG, et al., Study of Medical Testing for Cataract Surgery Team. Risks and benefits of anticoagulant and antiplatelet medication use before cataract surgery. Ophthalmology 2003; 110: 1784-1788.

7 Kallio H, Paloheimo M, Maunuksela EL. Haemorrhage and risk factors associated with retrobulbar/peribulbar block: a prospective study in 1383 patients. Br J Anaesth 2000; 85: 708-711.

8 Assia EI, Raskin T, Kaiserman I, Rotenstreich Y, Segev F. Effect of aspirin intake on bleeding during cataract surgery. J Cataract Refract Surg 1998; 24: 1243-1246.

9 Carter K, Miller KM. Phacoemulsification and lens implantation in patients treated with aspirin or warfarin. J Cataract Refract Surg 1998; 24: 1361-1364.

10 Gainey SP, Robertson DM, Fay W, Ilstrup D. Ocular surgery on patients receiving long-term warfarin therapy. Am J Ophthalmol 1989; 108: 142-146. 
11 Hall DL, Steen Jr WH, Drummond JW, Byrd WA. Anticoagulants and cataract surgery. Ophthalmic Surg 1988; 19: 221-222.

12 McCormack P, Simcock PR, Tullo AB. Management of the anticoagulated patient for ophthalmic surgery. Eye 1993; 7: 749-750.

13 Robinson GA, Nylander A. Warfarin and cataract extraction. Br J Ophthalmol 1989; 73: 702-703.

14 Morris A, Elder M. Warfarin therapy and cataract surgery. Clin Experiment Ophthalmol 2000; 28: 419-422.

15 The Royal College of Ophthalmologists. Cataract surgery guidelines. 2004. http://www.rcophth.ac.uk/docs/ publications/published-guidelines/ FinalVersionGuidelinesApril2007Updated.pdf.

16 Konstantatos A. Anticoagulation and cataract surgery: a review of the current literature. Anaesth Intensive Care 2001; 29: 11-18.

17 Leong JY, Baker RA, Shah PJ, Cherian VK, Knight JL. Clopidogrel and bleeding after coronary artery bypass graft surgery. Ann Thorac Surg 2005; 80: 928-933.

18 Chu MW, Wilson SR, Novick RJ, Stitt LW, Quantz MA. Does clopidogrel increase blood loss following coronary artery bypass surgery? Ann Thorac Surg 2004; 78: 1536-1541.

19 Ernst A, Eberhardt R, Wahidi M, Becker HD, Herth FJ. Effect of routine clopidogrel use on bleeding complications after transbronchial biopsy in humans. Chest 2006; 129: 734-737.

20 Nuutinen LS, Pihlajaniemi R, Saarela E, Karkola P, Hollmen A. The effect of dipyridamole on the thrombocyte count and bleeding tendency in open-heart surgery. I Thorac Cardiovasc Surg 1977; 74: 295-298.
21 Davies BR. Combined aspirin and clopidogrel in cataract surgical patients: a new risk factor for ocular haemorrhage? Br J Ophthalmol 2004; 88: 1226-1227.

22 Kumar N, Jivan S, Thomas P, McLure H. Sub-Tenon's anesthesia with aspirin, warfarin, and clopidogrel. J Cataract Refract Surg 2006; 32: 1022-1025.

23 Jaycock P, Johnston RL, Taylor H, Adams M, Tole DM, Galloway P et al. The Cataract National Dataset electronic multi-centre audit of 55567 operations: updating benchmark standards of care in the UK and internationally. EYE 2007. in press).

24 Service Implementation-Do Once and Share. Appendix P, Cataract National Dataset. 2006. http:// www.rcophth.ac.uk/docs/college/doas/ DOAS_Cataract_Final_Report_Ap pendix_P.xls.

25 El-Hindy N, Johnston RL, Jaycock P, Eke T, Braga AJ, Tole DM, et al., the UK EPR User Group. The Cataract National Dataset electronic multi-centre audit of 55567 operations: anaesthetic techniques and complications. EYE 2007. (in press).

26 Narendran N, Jaycock P, Johnston RL, Taylor H, Adams M, Tole DM et al. The Cataract National Dataset electronic multi-centre audit of 55567 operations: risk stratification for posterior capsule rupture and vitreous loss. EYE 2007. submitted).

27 Service Implementation - Do Once and Share. Visual Failure (Cataract) Action Team. Final Report 2006. http:// www.rcophth.ac.uk/docs/college/doas/ DOAS_Cataract_Action_Team_Final_Report_v1.0.DOC. 28 Javitt JC. Rule Britannia. Eye 2005; 19: 727-728. 